\title{
Ante natal care (ANC) utilization, dietary practices and nutritional outcomes in pregnant and recently delivered women in urban slums of Delhi, India: an exploratory cross-sectional study
}

Suparna Ghosh-Jerath ${ }^{1 *+}$, Niveditha Devasenapathy ${ }^{1+}$, Archna Singh $^{2}$, Anuraj Shankar $^{3}$ and Sanjay Zodpey ${ }^{1}$

\begin{abstract}
Background: Antenatal Care (ANC) is one of the crucial factors in ensuring healthy outcomes in women and newborns. Nutrition education and counselling is an integral part of ANC that influences maternal and child health outcomes. A cross sectional study was conducted in Pregnant Women (PW) and mothers who had delivered in the past three months; Recently Delivered Women (RDW) in urban slums of North-east district of Delhi, India, to explore ANC utilization, dietary practices and nutritional outcomes.
\end{abstract}

Methods: A household survey was conducted in three urban slums to identify PW and RDW. Socio-economic and demographic profile, various components of ANC received including nutrition counselling, dietary intake and nutritional outcomes based on anthropometric indices and anaemia status were assessed. Socio-demographic characteristics, nutrient intake and nutritional status were compared between those who availed ANC versus those who did not using logistic regression. Descriptive summary for services and counselling received; dietary and nutrient intake during ANC were presented.

Results: Almost $80 \%$ (274 out of 344) women received some form of ANC but the package was inadequate. Determinants for non-utilization of ANC were poverty, literacy, migration, duration of stay in the locality and high parity. Counselling on nutrition was reported by a fourth of the population. Nutrient intake showed suboptimal consumption of protein and micronutrients like iron, calcium, vitamin A, vitamin C, thiamine, riboflavin niacin, zinc and vitamin B12 by more than half of women. A high prevalence of anaemia among PW (85\%) and RDW (97.1\%) was observed. There was no difference in micronutrient intake and anaemia prevalence among women who received ANC versus who did not.

Conclusions: Pregnant women living in urban poor settlements have poor nutritional status. This may be improved by strengthening the nutrition counselling component of ANC which was inadequate in the ANC package received. Empowering community based health workers in providing effective nutrition counselling should be explored given the overburdened public health system.

Keywords: Pregnancy, Antenatal care, Nutritional status, Nutrition counselling, Dietary intake

\footnotetext{
* Correspondence: suparna.ghoshj@iiphd.org

${ }^{\dagger}$ Equal contributors

'Indian Institute of Public Health-Delhi, Public Health Foundation of India,

Plot No 47, Sector 44, Institutional area, Gurgaon 122002, Haryana, India

Full list of author information is available at the end of the article
} 


\section{Background}

Antenatal Care (ANC) is the key entry point for pregnant women to receive a broad range of health promotion and prevention services. WHO recommends a minimum of four ANC visits, ideally at 16, 24-28, 32 and 36 weeks and recommends health promotion including nutrition counselling as one of its important components besides others [1]. It has been shown that women attending regular ANC exhibit better knowledge, attitudes and antenatal practices compared to those not availing in several developing countries [2-4]. Nutrition education and counselling is a widely used strategy to improve the nutritional status of women during pregnancy that significantly influences foetal, infant and maternal health outcomes.

Systematic reviews on impact of antenatal dietary advice, nutrition education and counselling with or without nutrition supplementation report improved dietary intake and weight gain in mothers, reduced risk of anaemia and preterm delivery, increased head circumference and birth weight $[2,5,6]$. In spite of its known merits, Information, Education and Communication (IEC) during ANC along with nutrition and diet education is reported to be poorly executed and ANC is considered as a missed opportunity for IEC [7].

The availability of, and access to antenatal care is very variable across India with the key determinants being place of residence (urban/rural), socio-economic and several other cultural factors [8]. In the context of urban environment in India, there is a large inequity in access to quality ANC services. Economic and logistic barriers put the secondary care and private sector facilities out of reach of most poor urban residents [9], which could be the reason for most people living in urban poor settlements in India typically accessing the public health facilities for ANC [10]. Public sector urban health delivery system accessed by the underprivileged is far from adequate owing to high population to heath centre ratio, inadequately skilled staff, high staff turnover and absenteeism [11,12]. The need for strengthening the health education component of care in healthcare delivery system catering to the underprivileged that can engender changes in attitude and practice has been emphasized $[13,14]$. In the context of urban health system we could not locate studies in literature that quantify the counselling component provided during ANC at a health care facility. Studies have shown that pregnant women in urban poor settlements in Delhi had a poor dietary intake with majority of women consuming less than 50\% of recommended dietary allowances for protein, iron and vitamin A with their intake not being significantly different from their non-pregnant counterparts $[15,16]$.

AnteNatal and Child Health care in Urban sLums (ANCHUL) project aimed to develop, implement and evaluate the effectiveness of a complex intervention targeted at the community based health workers called Accredited Social Health Activists (ASHA) in increasing institutional delivery and improving maternal, neonatal and child healthcare practices in urban poor settlements of Delhi. During the formative phase of the project, a situational analysis was conducted and in this paper we present the findings on the availability and utilization of ANC services with a special focus on counselling, explore factors associated with ANC utilization and describe the nutrient adequacy of the diet consumed by the pregnant and recently delivered women along with their nutritional assessment.

\section{Methods \\ Study setting}

A cross sectional survey was conducted in three urban slums in India's national capital, Delhi, between November 2010 and March 2011. The detailed description of the study area and sampling method are described elsewhere [17]. Briefly, the three urban poor clusters namely CPJ, Buland Masjid and Chanderpuri were from three constituencies of North-East district of Delhi. This district is home to the highest number of slum dwellers compared to other districts of Delhi state.

\section{Study population}

All households (HHs) were approached to elicit information on socio-economic and demographic characteristics. During the survey we obtained a list of Pregnant Women (PW) and mothers who had given birth in the past 3 months (Recently Delivered Women (RDW)). These women were approached after 2 weeks of the initial household survey to collect detailed information about their ANC care, child birth, dietary practices and nutritional assessment. The study protocol was approved by Health Ministry Screening Committee of Government of India, institutional ethics committees of the Public Health Foundation of India, All India Institute of Medical Sciences, New Delhi, WHO Geneva and Harvard School of Public Health, Boston.

\section{Sample size}

The sample size for the survey was calculated for measuring the prevalence of institutional deliveries in urban slums of Delhi. For this outcome to be measured with $10 \%$ relative precision assuming $33 \%$ prevalence of institutional delivery in the urban poor of Delhi [18] we needed to interview 780 women who had given birth in past one year. To identify at least 750 mothers who gave birth in past one year we needed to cover a population of 30,000 which is approximately 6000 households (assuming a crude birth rate of 25/1000). 


\section{Data collection}

The household $(\mathrm{HH})$ survey was initiated only after obtaining consent from the cluster guardians. Lane to lane mapping exercise of the area ensured that all households were covered. During the mapping exercise the number of functional clinics and health posts were recorded irrespective of their registration status. From the PW and RDW who consented and were available on our revisit, information regarding utilization of ANC services and details of services offered during ANC visits were elicited by trained field interviewers using paper based forms. For assessing their dietary intake pattern, a diet survey using a 24 hour dietary recall for 2 consecutive days along with a food frequency questionnaire was conducted by trained nutritionists. Nutritional status was assessed by anthropometry (height and weight) using standard techniques and through biochemical assessment of haemoglobin status using the standard protocol for cyanmethemoglobin method. To gain an estimate of the weight gain trends in the pregnant women, a repeat weight measurement was taken after 2 weeks of the first measurement. Double data entry was done in a database designed in Microsoft Access with inbuilt validation checks. The food frequency was double entered in Microsoft Excel. The dietary recall which was taken as cooked weight from the respondent was converted into actual weights of raw foods consumed. The raw foods were then entered and converted into nutrients using a validated software DIET SOFT version 1.1 (Profound
Technical Solutions, New Delhi) which utilizes values from Nutritive Value of Indian Foods [19].

\section{Data analysis}

All data describing the socio-demographic profile and ANC utilization were summarized using descriptive statistics. The mean daily intake of the participants were computed and then compared with Recommended Dietary Allowances (RDA) for Indians [20]. In order to assess the diet quality, the adequacy of nutrient intake by each subject was computed in terms of Nutrient Adequacy Ratio (NAR) using NAR = Participant's nutrient intake of a day/ RDA of the respective nutrient. This data was further categorized into three groups (adequate $(\geq 1.00)$, fairly adequate $(0.66-<1.00)$ or inadequate $(<0.66)$ NAR for various nutrients). The adequacy of consumption of various food groups were assessed using the 24 hour dietary recall data and compared with recommended intakes [21]. All women based on their pregnancy status (pregnant/lactating) were classified into anaemia grades as per the WHO classification; (For pregnant women: Haemoglobin of $>11 \mathrm{~g} / \mathrm{dl}=$ no anaemia, $10-11 \mathrm{~g} / \mathrm{dl}=$ mild anaemia. For Lactating women $>12 \mathrm{~g} / \mathrm{dl}=$ no anaemia, 10-12 $\mathrm{g} / \mathrm{dl}=$ mild anaemia and $7-10 \mathrm{~g} / \mathrm{dl}=$ moderate anaemia,$<7 \mathrm{~g} / \mathrm{dl}=$ severe anaemia for both groups) [22]. Body Mass Index (BMI) (Weight in $\mathrm{kg}$ / height in metres) was calculated for only the RDW to categorize them into (nutritional grades of underweight or Chronic Energy Deficiency (CED) with

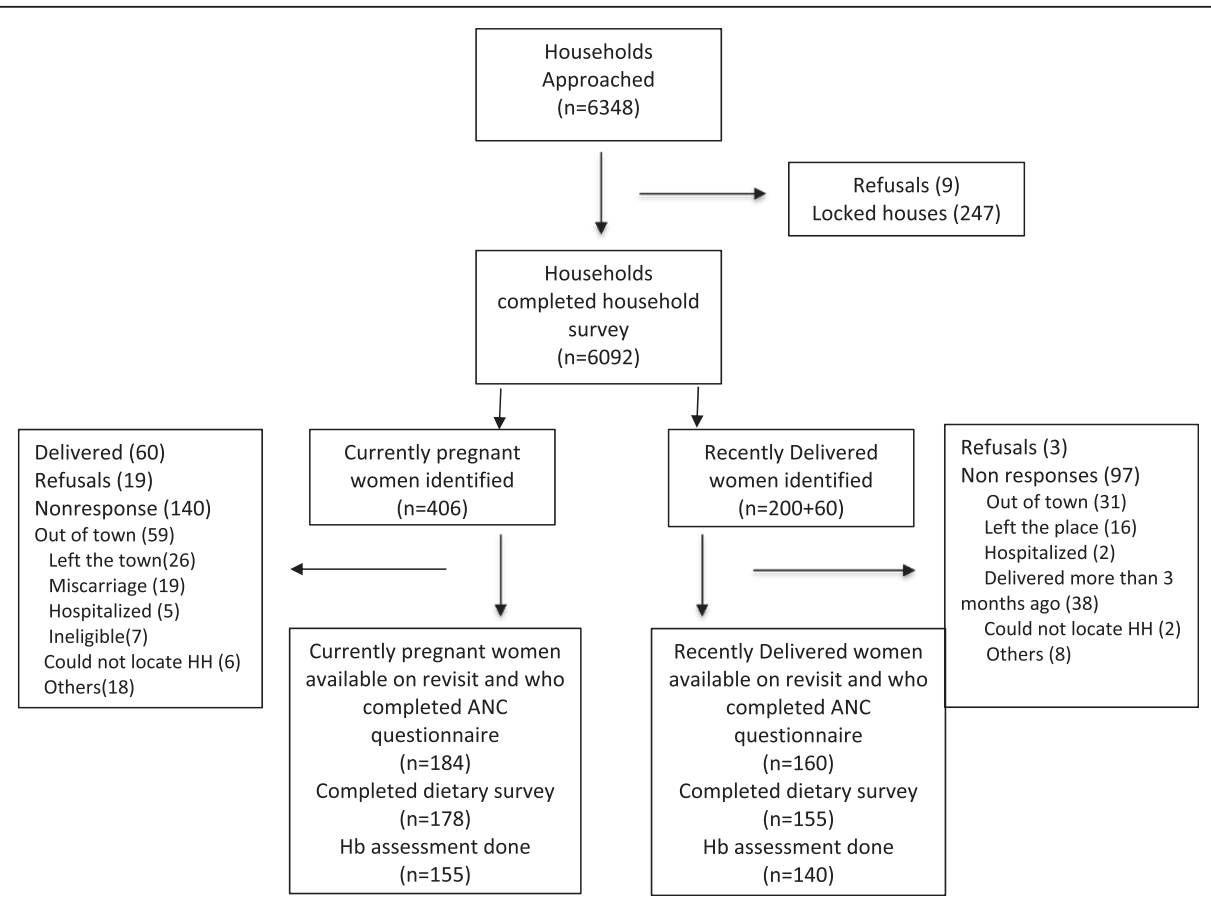

Figure 1 Recruitment summary of target population. 
Table 1 Characteristics of the households

\begin{tabular}{|c|c|c|c|}
\hline Characteristics & $\begin{array}{l}\text { CPW and RDW who participated } \\
(\mathrm{n}=344)\end{array}$ & $\begin{array}{l}\text { CPW and RDW who did not participate } \\
(n=261)\end{array}$ & P-value \\
\hline Nuclear family (\%) & $225(65.4)$ & $181(69.4)$ & 0.31 \\
\hline Spoken language Hindi & $298(86.6)$ & $230(88)$ & 0.21 \\
\hline Muslim (\%) & $254(73.84)$ & $200(76.6)$ & 0.43 \\
\hline \multicolumn{4}{|l|}{ Caste } \\
\hline General & $160(46.5)$ & $105(40.2)$ & \\
\hline $\mathrm{OBC}$ & $139(40.4)$ & $117(44.8)$ & 0.30 \\
\hline $\mathrm{SC} / \mathrm{ST}$ & $45(13.1)$ & $39(14.9)$ & \\
\hline Family size (SD) & $5.43(2.7)$ & $5.5(3.1)$ & 0.72 \\
\hline Durable housing (\%) & $274(79.6)$ & $213(81.6)$ & 0.45 \\
\hline Toilet facility within $\mathrm{HH}(\%)$ & $274(79.6)$ & $222(85.1)$ & 0.23 \\
\hline \multicolumn{4}{|l|}{ Head of household } \\
\hline Male (\%) & $299(86.9)$ & $222(85.1)$ & 0.51 \\
\hline Mean age(SD) & $38(13.4)$ & $37.7(14.1)$ & 0.83 \\
\hline |lliterate (\%) & $204(59.3)$ & $163(62.4)$ & 0.43 \\
\hline \multicolumn{4}{|l|}{ Socioeconomic status of HH (\%) } \\
\hline Poorest & $109(31.7)$ & $101(38.7)$ & \\
\hline Middle & $98(28.5)$ & $80(30.7)$ & 0.05 \\
\hline Richest & $137(39.8)$ & $80(30.7)$ & \\
\hline Migrated to Delhi & $197(57.3)$ & $141(54)$ & 0.42 \\
\hline Staying the same locality for $>5 \mathrm{yrs}(\%)$ & $263(76.5)$ & $196(75.1)$ & 0.169 \\
\hline $\begin{array}{l}\text { Distance to nearest public healthcare facility } \\
(<5 \mathrm{kms})(\%)\end{array}$ & $275(80)$ & $207(79.3)$ & 0.497 \\
\hline \multicolumn{4}{|l|}{ Facility visited for MCH services (\%) } \\
\hline Public & $262(76.2)$ & $201(77)$ & 0.304 \\
\hline Private & $59(17.2)$ & $36(13.8)$ & \\
\hline NGO & $5(1.5)$ & $3(1.2)$ & \\
\hline Others & $18(5.2)$ & $21(8)$ & \\
\hline Ration card & $152(44.2)$ & $113(43.3)$ & 0.758 \\
\hline BPL & $99(28.8)$ & $70(26.8)$ & 0.27 \\
\hline RSBY & $83(24.1)$ & $45(17.2)$ & 0.05 \\
\hline
\end{tabular}

Table 2 Profile and pregnancy details of the study population

\begin{tabular}{lll}
\hline Characteristics & CPW (n= 184) & RDW (n= 160) \\
\hline Age in years (SD) & $23.4(3.9)$ & $24.7(4.36)$ \\
Duration of pregnancy for CPW & $6.3(1.7)$ & NA \\
Illiterate (\%) & $88(47.8)$ & $88(55)$ \\
Homemaker & $180(97.8)$ & $156(97.5)$ \\
Marriage after 18 yrs & $161(87.5)$ & $136(85)$ \\
Pregnancy after 18 yrs* & $173(95)$ & $149(95)$ \\
First pregnancy & $64(34.8)$ & $41(25.6)$ \\
\hline
\end{tabular}

${ }^{*} \mathrm{n}$ for $\mathrm{CPW}=182 \mathrm{n}$ for RDW $=157$.
BMI $<18.5 \mathrm{~kg} / \mathrm{m}^{2}$, normo-weight $18.5-23 \mathrm{~kg} / \mathrm{m}^{2}$ and overweight or obese $>23 \mathrm{~kg} / \mathrm{m}^{2}$ ) as per WHO [23]. The weight gain in PW was assessed by comparing them with Indian standards for recommended weight gain in trimester 2 (60 g/day) and trimester 3 (54 g/day) of pregnancy [20].

A comparison of demographic characteristics between those who availed ANC and those who did not was done using simple logistic regression. Adjusted analysis using logistic regression was performed with addition of all socio-demographic characteristics. Socioeconomic categories were derived from household income, assets and dwelling characteristics using principal component analysis. Crude and adjusted OR with 95\% CI are presented along with two-sided $\mathrm{p}$ - values ( $\mathrm{p}$-value $<0.05$ was 
Table 3 Information on ANC received

\begin{tabular}{ll}
\hline Services received & $\mathbf{N}=\mathbf{3 4 4}$ \\
\hline Some kind of ANC & $273(79.36)$ \\
Did not avail ANC at a facility & $71(20.6)$ \\
Availed ANC at facility $(\mathrm{n}=273)$ & \\
$\quad$ Public facility & $197(72.2)$ \\
$\quad$ Private facility & $59(21.6)$ \\
$\quad$ NGO & $17(6.2)$ \\
\% who registered for ANC $(\mathrm{n}=272)$ in & \\
First trimester & $119(43.8)$ \\
$\quad$ Second trimester & $135(49.6)$ \\
Third trimester & $18(6.6)$ \\
Received prescription for & \\
Iron tablet & $242(70.4)$ \\
$\quad$ From public hospital & $178(73.9)$ \\
Reported to consume regularly & $191(78.9)$ \\
Calcium & $245(71.43)$ \\
From public hospital & $196(80)$ \\
Reported to consume regularly & $172(72.6)$ \\
TT received ( $n=170)$ & $143(84.1)$ \\
Aware about ICTC $(n=342)$ & $128(37.4)$ \\
Visited ICTC ( $n=128)$ & $21(16.4)$ \\
Both husband and wife & $79(61)$ \\
One of them & $28(22.6)$ \\
\hline Did not visit &
\end{tabular}

considered statistically significant). All data were analysed using Stata 13 [24]. To explore for possible selection bias due to high non-response rates, statistical comparison of the household demographic information between responders and non-responders was done using Pearson chi-squared test for categorical variables and student $t$-test for continuous variable.

\section{Results}

Of the 6348 households in the three defined areas, 6092 (96\%) households participated in the HH survey. From a total population of 32,034, we identified 406 selfdeclared pregnant women and 200 mothers who had given birth in past three months. Of these only 184 pregnant women and 160 mothers participated in the detailed survey. The key reason for low response rate when they were approached after 2 weeks, was due to women moving to their maternal home for child birth. The study recruitment summary is elaborated in Figure 1. Socio-economic and demographic characteristics of the households of the study population is described in Table 1. There was no significant difference in household characteristics between those who were available for the detailed interview and those who were not.. The mean age was 24 years with most $(86.2 \%)$ reported having married after attaining 18 years of age and $65.4 \%$ living in nuclear families (Tables 1 and 2). Half of the women were illiterate and almost all (97.7\%) were homemakers.

\section{Availability of ANC and other health care services}

All three clusters had access to some kind of health care facility (government/private) for maternal, neonatal and child health $(\mathrm{MNCH})$ care within 2.5 kilometres $(\mathrm{km})$ radius. One referral hospital was situated at a distance of $5 \mathrm{kms}$ and several other referral hospitals beyond $10 \mathrm{~km}$. In two out of three clusters, no private nursing home was present. A Government-run $\mathrm{MCH}$ centre and Rashtriya Swasthya Bima Yojana (RSBY) (a public health insurance scheme for people belonging to unorganized sector) empanelled hospital was present within each of two clusters. The Primary Urban Health Centre (PUHC) was situated within one of the slum clusters. A total of 17 private clinics (registered and unregistered) and one laboratory was present in the study area. Though $28 \%$ of the women reported presence of any community health worker in their area, only one pregnant woman reported home visits by a health worker.

\section{Utilization of ANC}

Of the 344 women $70(20.6 \%, 95 \%$ CI 16,25$)$ did not avail any kind of ANC services. A detailed description of ANC service utilization is provided in Table 3. Out of 274 women who availed ANC services, 44\% (95\% CI 38, 50) registered for ANC in the first trimester. The univariable analysis comparing women who availed ANC with those who did not, showed association with $\mathrm{HH}$ factors viz. socioeconomic status, religion, belonging to Delhi, and duration of stay in the locality and individual factors namely schooling, age at marriage and parity (Table 4). On multivariable analysis adjusted for rest of the factors, richer households (OR 2.13 [95\% CI 0.98, 4.62]), being resident of the locality for a duration $>5$ years (OR 2 [95\% CI 1.06, 3.77]), women's schooling (OR 2.15 [95\%CI1.1, 4.17]) and first pregnancy (OR 2.58 $[95 \% \mathrm{CI} 1.19,5.58])$ were strongly associated to availing ANC services at a facility.

\section{Services and counselling received during ANC}

The medical care as a part of ANC were reported to be done in more than $80 \%$ of the women availing ANC (Table 5). However, when a correlation was seen between the components, it was moderate, except for correlation between blood and urine examination and iron and folic acid (IFA) and calcium prescription which was high (not shown in the table). Regular intake of IFA and calcium tablets respectively, was reported by $78.9 \%$ and $72 \%$. The common reasons cited for erratic intake were 
Table 4 Association of socio demographic profile and availing ANC

\begin{tabular}{|c|c|c|c|c|}
\hline Characteristics & $\begin{array}{l}\text { Availed ANC } \\
(n=274)\end{array}$ & $\begin{array}{l}\text { Did not avail ANC } \\
(\mathrm{n}=70)\end{array}$ & $\begin{array}{l}\text { Crude OR }(95 \% \mathrm{Cl}), \\
\text { p value }\end{array}$ & $\begin{array}{l}\text { Adjusted } \mathrm{OR}^{*}(95 \% \mathrm{Cl}) \text {, } \\
\text { p value }\end{array}$ \\
\hline \multirow[t]{2}{*}{ Family size } & $5.5(2.70)$ & $5.3(2.65)$ & $1.03(0.93,1.14)$ & $1(0.87,1.14)$ \\
\hline & & & 0.47 & 0.98 \\
\hline \multicolumn{5}{|l|}{ Socio-economic Scale (SES) of $\mathrm{HH}^{* *}$} \\
\hline Poorest & $71(26.01)$ & $38(53.52)$ & 1 & 1 \\
\hline Middle & $82(30.04)$ & $16(22.54)$ & $2.74(1.41,5.33)$ & $2.29(0.98,4.62)$ \\
\hline \multirow[t]{2}{*}{ Richest } & $120(44.1)$ & $17(22.94)$ & $3.77(1.98,7.18)$ & $2.13(0.40,2.1)$ \\
\hline & & & 0.001 & 0.039 \\
\hline \multirow[t]{2}{*}{ Nuclear family } & $173(63.4)$ & $52(73.24)$ & $0.63(0.35,1.13)$ & $1.21(0.58,2.55)$ \\
\hline & & & 0.12 & 0.6 \\
\hline \multirow[t]{2}{*}{ Non-Muslim } & $73(26.74)$ & $17(23.94)$ & $1.16(0.63,2.12) 0.63$ & $1.1(0.54,2.26)$ \\
\hline & & & & 0.77 \\
\hline \multirow[t]{2}{*}{ Schooling of Head of Household } & $107(39.2)$ & $20(28.2)$ & $1.64(0.92,2.91)$ & $1.23(0.62,2.4)$ \\
\hline & & & 0.08 & 0.54 \\
\hline \multirow[t]{2}{*}{ Schooling of the woman } & $150(55)$ & $18(25.35)$ & $3.59(2,6.45)$ & $2.15(1.10,4.18)$ \\
\hline & & & $<0.001$ & 0.016 \\
\hline \multirow[t]{2}{*}{ Belong to Delhi } & $124(45.42)$ & $23(32.4)$ & $1.73(1.001,3.01)$ & $1.23(0.67,2.3)$ \\
\hline & & & 0.046 & 0.49 \\
\hline \multirow[t]{2}{*}{ Longer duration of stay in the locality ( $>5$ years) } & $221(81)$ & $42(59.2)$ & $2.94(1.67,5.14)$ & $2(1.06,3.77)$ \\
\hline & & & $<0.001$ & 0.032 \\
\hline \multirow[t]{2}{*}{ Age at marriage $(\%)>18$ years } & $241(88.28)$ & $56(78.9)$ & $2.02(1.023 .97)$ & $1.65(0.78,3.52)$ \\
\hline & & & 0.043 & 0.18 \\
\hline \multirow[t]{2}{*}{ First pregnancy /child } & $95(34.8)$ & $10(14.1)$ & $3.26(1.59,6.64)$ & $2.58(1.19,5.58)$ \\
\hline & & & 0.0004 & 0.016 \\
\hline
\end{tabular}

*Adjusted using multiple logistic regression method; **The SES scale is a composite of house type, floor, house ownership, separate kitchen, TV, Refrigerator, mobile phone, washing machine, total $\mathrm{HH}$ income, number of rooms by principal component analysis.

"Just don't feel like" (33\% for IFA and 41\% for calcium), "Felt uneasy" (33\% for IFA and calcium), "Gastric trouble" (19\% for IFA and 12\% for calcium). The counselling received during ANC visits for various issues listed in the table varied between $35-80 \%$ with counselling on themes like early initiation of breast feeding, exclusive breast feeding (EBF) and family planning (FP) reported less frequently. Additional counselling on managing frequently occurring symptoms was reported by only $30 \%$. In general a higher proportion of RDW reported receiving counselling services as compared to PW.

\section{Satisfaction with the ANC services}

About 68\% respondents reported that they were satisfied with the ANC services availed. As seen in Figure 2 the key reason for satisfaction and dissatisfaction was based on their perception of quality of care and behaviour of the care provider.

\section{Dietary and nutrient intake}

The mean nutrient intake compared with the RDA for sedentary activity in PW and RDW is shown in Table 6.
The majority of PW and RDW had an inadequate nutrient adequacy ratio NAR $(<0.66)$ with respect to protein, and micronutrients like iron, calcium, vitamin A, vitamin $C$, thiamine, riboflavin, niacin, zinc and vitamin B12. One third of women also had an inadequate intake of energy (RDW (34.2\%), PW (36\%)).

A comparison of dietary adequacy in women who availed ANC versus those who did not, showed no association, except for protein intake which was lower in women who did not avail ANC $(p=0.019)$. However, these results need to be interpreted with caution owing to the multiple hypotheses tests done in a relatively small sample. The food consumption pattern based on the food frequency questionnaire (FFQ) showed a daily consumption of cereals, vegetables, milk, fats and sugar. However, when compared with the quantitative estimates from the 24 hour recall data, the mean consumption of vegetables $(10 \%)$ and milk $(60 \%)$ were below recommended intakes. Majority of the women reported consuming fruits, green leafy vegetables, pulses/legumes and flesh foods only 1-2 times a week with a low mean consumption per day as compared to recommended 
Table 5 Services and counselling received during ANC

\begin{tabular}{|c|c|c|c|}
\hline & Overall $(n=279)$ & CPW $(n=144)$ & RDW $(n=135)$ \\
\hline \multicolumn{4}{|l|}{ Medical care } \\
\hline Past history was asked & $227(81.4)$ & $117(81.3)$ & $110(81.5)$ \\
\hline Physical examination & $245(87.8)$ & $124(86.1)$ & $121(89.6)$ \\
\hline Body weight measured & $235(84.2)$ & $120(83.3)$ & $115(85.2)$ \\
\hline Blood Pressure measured & $247(88.5)$ & $126(87.5)$ & $121(89.6)$ \\
\hline Blood test done & $229(82)$ & $110(76.4)$ & $119(88.2)$ \\
\hline Urine test done & $226(81)$ & $107(74.3)$ & $119(88.2)$ \\
\hline IFA prescription given & $230(82.4)$ & $113(78.5)$ & $117(86.7)$ \\
\hline Calcium prescription given & $232(83.2)$ & $113(78.5)$ & $119(88.2)$ \\
\hline \multicolumn{4}{|l|}{ Counselling on ANC } \\
\hline Regular follow-up & $198(71)$ & $94(65.3)$ & $104(77.1)$ \\
\hline Hospital birthing & $170(60.9)$ & $82(56.9)$ & $88(65.2)$ \\
\hline Importance of $\pi$ & $217(77.8)$ & $104(72.2)$ & $113(83.7)$ \\
\hline Regular IFA & $218(78.1)$ & $107(74.3)$ & $111(82.2)$ \\
\hline Diet & $164(58.8)$ & 70 (48.6) & $94(69.6)$ \\
\hline Breast feeding initiation & $110(39.4)$ & $41(28.5)$ & $69(51.1)$ \\
\hline Exclusive breast feeding & $118(42.3)$ & $45(31.3)$ & $73(54.1)$ \\
\hline Family planning & $104(37.3)$ & $43(29.9)$ & $61(45.2)$ \\
\hline \multicolumn{4}{|c|}{ Counselling on dealing with symptoms } \\
\hline Vomiting & $86(30.82)$ & $38(26.4)$ & $48(35.6)$ \\
\hline Constipation & $49(17.6)$ & $23(15.9)$ & $26(19.3)$ \\
\hline Gastric fullness & $53(19)$ & $26(18.1)$ & $27(20)$ \\
\hline Pain & $55(19.8)$ & $26(18.2)$ & $29(21.5)$ \\
\hline Swelling & $56(20.1)$ & $26(18.2)$ & $30(22.2)$ \\
\hline Headache & $67(24.1)$ & $29(20.1)$ & $38(28.2)$ \\
\hline Bleeding & $72(25.8)$ & $33(22.9)$ & $39(28.9)$ \\
\hline Fatigue & $83(29.8)$ & $37(25.7)$ & $46(34.1)$ \\
\hline
\end{tabular}

(CPW: Currently Pregnant Women, RDW: Recently Delivered Women, ANC- Antenatal care, TT: Tetanus Toxoid, IFA: Iron and Folic Acid).

intakes. The commonly consumed packaged food products both labelled and unlabelled, included rusk (baked crackers) (89\%), biscuits (76\%) and bhujia, an Indian savoury fried snack made with chickpea flour (60\%). These products are known sources of saturated fat, trans-fats, energy and salt $[25,26]$.

\section{Nutritional status assessment}

After removing the outliers, 59\% of PW in the second trimester whose repeat weights were available after a 2 week interval $(n=66)$ had a weight gain of less than $60 \mathrm{~g}$ /day (as per recommendations) and 53\% of PW in third trimester $(n=60)$ had a weight gain of less than $54 \mathrm{~g} /$ day (as per recommendations). There was no association between weight gain patterns during the second and the third trimester of pregnancy and availing $\mathrm{ANC}(\mathrm{p}=0.27$; $\mathrm{p}=0.45)$. Among the RDW, $16 \%$ had CED as estimated by a BMI of less than 18.5. The prevalence of any anaemia was $85 \%$ among PW and $97.1 \%$ in RDW. The prevalence of severe anaemia was $18 \%$ (95\% CI 12, 24) and $15 \%(95 \%$ CI 9, 22) in PW and RDW, respectively. There was no statistically significant difference in mean haemoglobin levels between those who availed ANC and those who did not.

\section{Discussion}

This survey from the urban slums of Delhi, highlights various facets of ANC services offered, dietary intake patterns and nutritional status of pregnant women and lactating mothers. Though most of the women surveyed received some kind of antenatal care, the complete ANC package especially the counselling component was observed to be inadequate. The nutrient intake in the study population, showed suboptimal consumption of micronutrients, inadequate weight gain and high prevalence of 


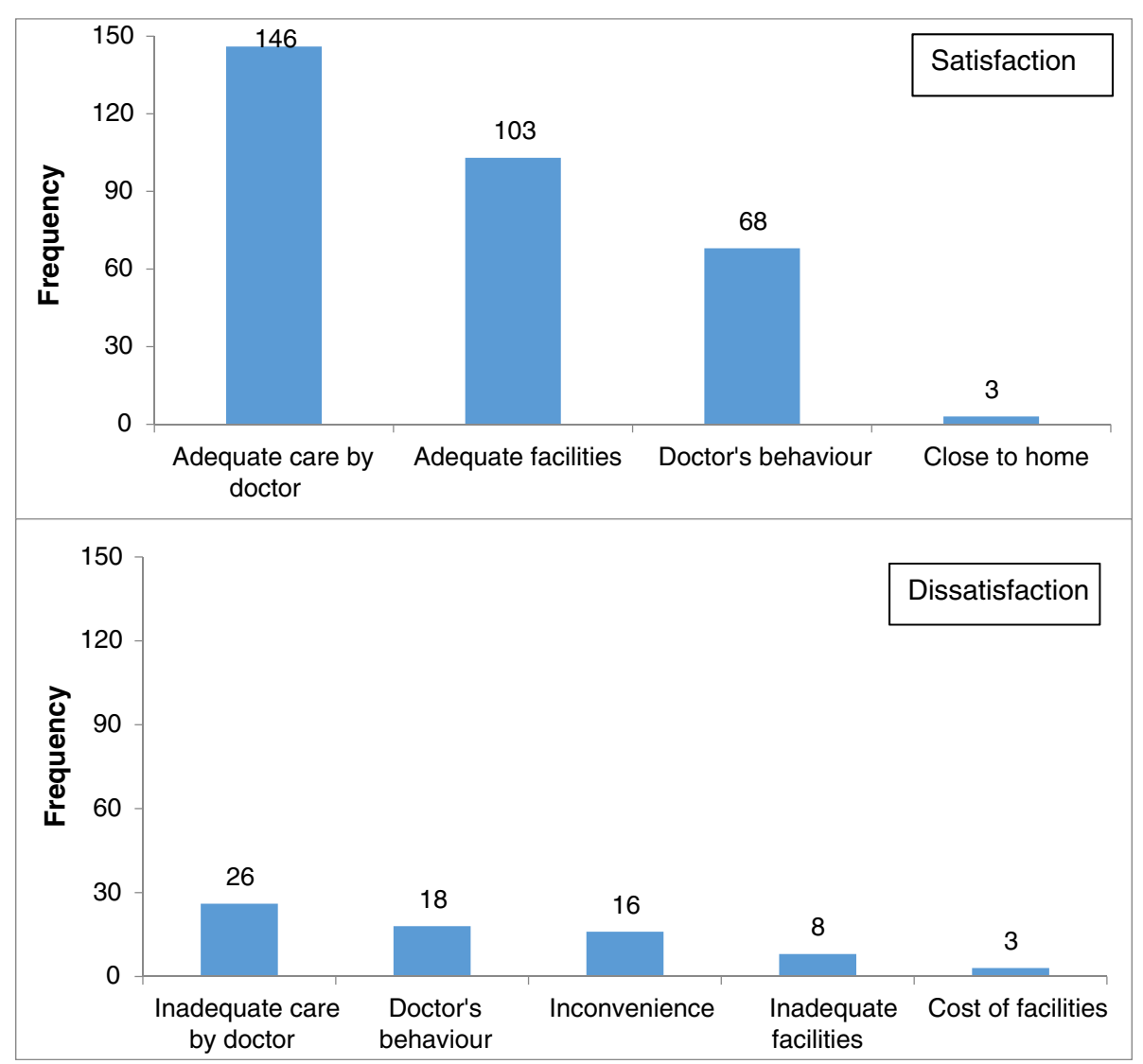

Figure 2 Reasons for satisfaction and dissatisfaction with the ANC services received perception of the women.

nutritional anaemia irrespective of ANC received. The women who availed ANC were mostly satisfied with the care they received.

In our study population $20 \%$ of women did not avail any ANC services at a health facility which is almost similar to the NFHS-3 Delhi slum data (25\%), but higher when compared to a slum survey from Mumbai where only $7 \%$ of women did not avail any ANC [27]. In our study the determinants for non-utilization were poverty, literacy, migration, duration of stay in the locality and high parity which was similar to a study using NFHS data [28] and the determinants for home delivery in this population [17].

The women we interviewed reported clinical examination, IFA and calcium prescription and TT vaccination as services provided under ANC. Partial ANC service provision was reported in a study in Agra district of Uttar Pradesh where more than 50\% were prescribed IFA and received TT but only a third of the pregnant women underwent abdominal examination and had BP measurements taken [29]. Only a fourth of our study population reported receiving counselling on diet and exclusive breast feeding. Our data also suggest that counselling was provided more towards the later stages of pregnancy as this service provision was reported more often by RDWs than PWs. This could limit the gains expected out of these sessions in bringing about behaviour change that is most critical in the earlier stages of pregnancy to achieve a greater impact on health outcomes.

The dietary intake especially protein and micronutrient intake was sub-optimal. The mean energy intake of our study population was higher than reported in other studies in urban poor settlements of Delhi $[15,16]$. However, micronutrient intakes especially of iron and vitamin A were lower in a higher proportion of our study population as compared to the study by Kapil et al. [15]. The quantitative estimates of consumption of micronutrient rich food sources like green leafy vegetables and seasonal fruits were low, while the consumption of unhealthy sources of fats and energy were high. Low cost dietary sources of micronutrients were available in the food environment of the community under study. However, culturally dictated food fads and nutritional taboos during pregnancy [30] might have prevented the women from consuming locally available low cost food. Further, despite the prescription and availability of nutritional supplements like IFA and calcium, a high prevalence of iron deficiency was 
Table 6 Nutrient intake and Nutrient Adequacy Ratio (NAR) of the study population

\begin{tabular}{|c|c|c|c|c|c|c|c|c|c|c|c|c|}
\hline \multirow[t]{2}{*}{ Nutrient } & \multicolumn{3}{|c|}{ Pregnant women $(n=178)$} & \multicolumn{3}{|c|}{ Nutrient Adequacy Ratio } & \multicolumn{3}{|c|}{$\begin{array}{l}\text { Recently delivered women } \\
(n=155)\end{array}$} & \multicolumn{3}{|c|}{ Nutrient Adequacy Ratio } \\
\hline & $\begin{array}{l}\text { RDA } \\
(2010)\end{array}$ & $\begin{array}{l}\text { Mean } \\
\text { intake } \pm \text { SD }\end{array}$ & $\%$ adequacy & $\begin{array}{l}\text { Inadequate } \\
(<.66 \text { of RDA) } \\
\mathrm{n}(\%)\end{array}$ & $\begin{array}{l}\text { Fairly adequate } \\
(.66-<1.00 \text { of the } \\
\text { RDA) } n(\%)\end{array}$ & $\begin{array}{l}\text { Adequate } \\
(\geq 1) \mathrm{n}(\%)\end{array}$ & $\begin{array}{l}\text { RDA } \\
(2010)\end{array}$ & $\begin{array}{l}\text { Mean } \\
\text { intake } \pm \text { SD }\end{array}$ & $\%$ adequacy & $\begin{array}{l}\text { Inadequate } \\
(<.66 \text { of RDA) } \\
\mathrm{n}(\%)\end{array}$ & $\begin{array}{l}\text { Fairly adequate } \\
(.66-<1.00 \text { of } \\
\text { the RDA) } n(\%)\end{array}$ & $\begin{array}{l}\text { Adequate } \\
(\geq 1) \mathrm{n}(\%)\end{array}$ \\
\hline Energy (kcal) & $2250^{*}$ & $2021 \pm 734$ & 89.8 & - & - & - & $2500^{*}$ & $2277 \pm 757$ & 91.1 & - & - & - \\
\hline Protein (g) & 82.2 & $53.3 \pm 21.9$ & 64.8 & $106(59.6)$ & $57(32.0)$ & $15(8.4)$ & 77.9 & $63.4 \pm 20.9$ & 81.4 & $44(28.4)$ & $79(51.0)$ & $32(20.6)$ \\
\hline Fat (g) & $\begin{array}{l}\text { atleast } \\
20 \mathrm{E} \% * *\end{array}$ & $71.6 \pm 40.1$ & 143.2 & - & - & - & $\begin{array}{l}\text { atleast } \\
20 \text { E\%** }\end{array}$ & $79.1 \pm 45.8$ & 158.2 & - & - & - \\
\hline Iron (mg) & 35 & $12.0 \pm 5.8$ & 34.3 & $170(95.5)$ & $8(4.5)$ & 0 & 25 & $14.0 \pm 5.8$ & 56 & $111(71.6)$ & $40(25.8)$ & $4(2.6)$ \\
\hline Calcium (mg) & 1200 & $568.0 \pm 370.2$ & 47.3 & $145(81.5)$ & $26(14.6)$ & $7(3.9)$ & 1200 & $634 \pm 441$ & 52.8 & $109(70.3)$ & $33(21.3)$ & $13(8.4)$ \\
\hline Folic acid (total) (mcg) & 500 & $115 \pm 60.5$ & 23 & $177(99.4)$ & $1(.6)$ & 0 & 300 & $144.0 \pm 78.3$ & 48 & $132(85.2)$ & $16(10.3)$ & $7(1.6)$ \\
\hline Vitamin A (mcg) & 800 & $266 \pm 211.2$ & 33.3 & $160(89.9)$ & $15(8.5)$ & $3(1.7)$ & 950 & $330 \pm 309$ & 34.7 & $131(84.5)$ & $17(11.0)$ & $7(4.5)$ \\
\hline Vitamin C (mg) & 60 & $44 \pm 38$ & 73.3 & $107(60.1)$ & $30(16.9)$ & $41(23.0)$ & 80 & $31.0 \pm 30.0$ & 38.8 & $135(87.1)$ & $12(7.7)$ & $8(5.2)$ \\
\hline Thiamin (mg) & 1.2 & $1.1 \pm 0.6$ & 91.7 & $57(32.0)$ & $56(31.5)$ & $65(36.5)$ & 1.3 & $1.4 \pm 0.6$ & 107.7 & $25(16.1)$ & $58(37.4)$ & $72(46.5)$ \\
\hline Riboflavin (mg) & 1.4 & $0.8 \pm 0.4$ & 57.1 & $117(65.7)$ & $45(25.3)$ & $16(9.0)$ & 1.5 & $0.96 \pm 0.5$ & 64 & $85(54.8)$ & $46(29.7)$ & $24(15.5)$ \\
\hline Niacin (mg) & 14 & $10 \pm 5.4$ & 71.4 & $94(52.8)$ & $54(30.3)$ & $30(16.9)$ & 16 & $11.0 \pm 5.5$ & 68.8 & $77(49.7)$ & $54(34.8)$ & $24(15.5)$ \\
\hline Zinc (mg) & 12 & $5.5 \pm 2.4$ & 45.8 & $150(84.3)$ & $26(14.6)$ & $2(1.1)$ & 12 & $6.3 \pm 2.50$ & 52.5 & $123(79.4)$ & $28(18.1)$ & $4(2.6)$ \\
\hline Vitamin B12 (mg) & 1.20 & $0.54 \pm 0.68$ & 45 & $140(78.7)$ & 19 (10.7) & 19 (10.7) & 1.5 & $1.50 \pm 6.31$ & 100 & $97(62.6)$ & $21(13.5)$ & 37 (23.9) \\
\hline
\end{tabular}

*Estimated Average Requirement (EAR) for Energy **\% contribution of fat calories in the total energy intake Bold: Indicates that $>50 \%$ of women had inadequate intake. 
recorded. All these findings point to the compelling and vital role that nutritional counselling can play during ANC visits to promote locally available, affordable micronutrient rich food sources. This along with reinforcement for compliance to nutritional supplements, may effectively address adverse health outcomes like anaemia and inadequate weight gain during pregnancy. As a corollary, this opportunity, if missed, could potentially retard efforts to improve maternal and child health despite the intensive resource inputs that are noticeably being allocated for this purpose.

In the present study, $75 \%$ women availed ANC from a public health facility in contrast to the Mumbai survey where an equal proportion of women availed the public and private sector health facilities [27]. The NFHS 3 data on ANC utilization cites the reasons for preferential utilization of private health care over public facilities (for those who can afford it) as being due to ineffective outreach, overcrowding, and poor quality of services in the urban public health system [28]. Studies from subSaharan Africa have also documented the severe shortage of health workers in hindering the capacity of health systems to deliver the required services [31]. Keeping in view the dependence of the urban poor on the overburdened and overcrowded public health facility, the counselling component may perhaps be effectively provided through the continuum of care approach [1] and utilizing the trained community based health workers. Studies from sub-Saharan Africa and Bangladesh have shown that health extension programs aiming to increase access to and equity in essential health care through community based outreach health services at the doorsteps of the residents have contributed in improving contraceptive use and utilization of some components of maternal health services [32-35]. We observed a very nominal presence of health workers in the community. Under the Delhi State Health Mission, the community health workers called ASHAs (Accredited Social Health Activists) are being recruited and trained to provide community based maternal and child health services in urban slums. Though health promotion is one of the important mandates for this cadre, capacity building for the specialized skills needed to provide effective counselling is much desirable. A systematic review has underscored the effectiveness of nutrition training for health workers in improving care providers' child feeding practices in terms of feeding frequency, energy intake, and dietary diversity of children aged six months to 2 years [36]. Through the ANCHUL project, we intend to explore the effectiveness of utilizing community health workers i.e. ASHAs in decentralizing the workload of health promotion which would lead to effective sharing of counselling services between health facilities and community health workers. Further research on this aspect in the urban
Indian context is required to demonstrate the effectiveness of role of ASHAs in nutrition counselling and improving health outcomes.

Some of the potential limitations in this study were (1) all information on ANC services received were based on recall which might have led to recall bias; (2) dietary intake data were collected for only 2 days in one particular season, which might not be representative of the habitual dietary intake of the population; (3) weight gain pattern measured needs to be interpreted with caution as weights were measured only at two time points, a fortnight apart; and (4) the sampling frame was only from 3 slum clusters from one of the districts of Delhi, which might not be representative of entire urban poor population.

\section{Key messages}

- Women in the urban poor settlements of Delhi accessed some form of ANC but the complete package of care especially the counselling component was grossly inadequate.

- Irrespective of the ANC received, the dietary intake of pregnant women was suboptimal, with poor weight gain and high prevalence of anemia.

- There is a need for strengthening the nutrition counselling component of ANC.

- Empowering community based health care workers in providing effective nutrition counselling should be explored given our overburdened public health system.

\section{Abbreviations}

ANC: Antenatal care; WHO: World health organization; IEC: Information education and communication; PW: Pregnant women; RDW: Recently delivered women; HH: Households; RDA: Recommended dietary allowance; NAR: Nutrient adequacy ratio; BMI: Body mass index; CED: Chronic energy deficency; PUHC: Primary urban health centre; RSBY: Rashtriya Swasthya Bima Yojana; FP: Family planning; FFQ: Food frequency questionnaire; EBF: Exclusive breast feeding ASHA, Accredited social health activist; ANCHUL: Antenatal and child health care in urban slums; TT: Tetanus toxoid; IFA: Iron and folic acid.

\section{Competing interests}

The authors declare that they have no competing interests.

\section{Authors' contributions}

SGJ and ND conceived and designed the study with additional inputs from AHS and SZ. SGJ and AS supervised the data collection. AS analysed the blood samples and ND analysed the data. SGJ and ND jointly prepared the first draft of the manuscript. All authors contributed to critique and modification of the manuscript SGJ had full access to all the data in the study and had final responsibility for the decision to submit for publication. All authors read and approved the final manuscript.

\section{Authors' information}

Suparna Ghosh-Jerath and Niveditha Devasenapathy are co-first authors.

\section{Acknowledgements}

We would like to acknowledge all the families who volunteered to provide data for this survey. We thank the efforts of field staff (Field coordinators, Field supervisor, and Nutrition interns), data manager and data entry operators. This work is funded by WHO, Geneva (Alliance for Health Policy 
and Systems Research (HSS/AHPSR), The Special Programme for Research and Training in Tropical Diseases (IER/TDR), The Special Programme of Research, Development and Research Training in Human Reproduction (HRP), Child and Adolescent Health and Development (FCH/CAH)) (Grant 2011/139172-0)

\section{Author details}

${ }^{1}$ Indian Institute of Public Health-Delhi, Public Health Foundation of India, Plot No 47, Sector 44, Institutional area, Gurgaon 122002, Haryana, India. ${ }^{2}$ Department of Biochemistry, All India Institute of Medical Sciences, Ansari Nagar, New Delhi 110029, India. ${ }^{3}$ Department of Nutrition, Harvard School of Public Health, 665 Huntington Avenue, Boston, MA 02115, USA.

\section{Received: 5 January 2015 Accepted: 25 February 2015}

\section{Published online: 20 March 2015}

\section{References}

1. Working with individuals, families and communities to improve maternal and newborn health. Making Pregnancy Safer Initiative, World Health Organization. 2003. http://apps.who.int/iris/bitstream/10665/84547/3/ WHO_MPS_09.04_eng.pdf?ua=1 (accessed 24/03/15).

2. Girard AW, Olude $O$. Nutrition education and counselling provided during pregnancy: effects on maternal, neonatal and child health outcomes. Paediatr Perinat Epidemiol. 2012;26 Suppl 1:191-204. doi: 10.1111/ j.1365-3016.2012.01278.x

3. Perumal N, Cole DC, Ouedraogo HZ, Sindi K, Loechl C, Low J, et al. Health and nutrition knowledge, attitudes and practices of pregnant women attending and not-attending ANC clinics in Western Kenya: a cross-sectional analysis. BMC Pregnancy Childbirth. 2013;13:146. doi: 10.1186/1471-2393-13-146.

4. Alam AY, Qureshi AA, Adil MM, Ali H. Comparative study of knowledge, attitude and practices among antenatal care facilities: Utilizing and non-utilizing women. J Pak Med Assoc. 2005;55(2):53-6.

5. Bhutta ZA, Das JK, Rizvi A, Gaffey MF, Walker N, Horton S, et al. Evidence-based interventions for improvement of maternal and child nutrition: what can be done and at what cost? Lancet. 2013;382(9890):452-77. doi: 10.1016/ S0140-6736(13)60996-4.

6. Ota E, Tobe-Gai R, Mori R, Farrar D. Antenatal dietary advice and supplementation to increase energy and protein intake. Cochrane Database Syst Rev. 2012;9:CD000032. doi: 10.1002/14651858.CD000032.pub2.

7. Anya SE, Hydara A, Jaiteh LE. Antenatal care in The Gambia: missed opportunity for information, education and communication. BMC Pregnancy Childbirth. 2008:8:9. doi: 10.1186/1471-2393-8-9.

8. Say L, Raine R. A systematic review of inequalities in the use of maternal health care in developing countries: examining the scale of the problem and the importance of context. Bull World Health Organ. 2007;85(10):812-9.

9. Yadav K, Nikhil S, Pandav CS. Urbanization and health challenges: need to fast track launch of the national urban health mission. Indian J Community Med. 2011:36(1):3-7. doi: 10.4103/0970-0218.80785.

10. National Family Health Survey (NFHS-3), 2005-06, India: Key Findings. Mumbai: IIPS. Available at http://cbhidghs.nic.in/writereaddata/linkimages/ NFHS-3\%20key\%20Findings5456434051.pdf. (accessed on $9^{\text {th }}$ June).

11. Health of the Urban Poor in India. Key Result from the re-analysis of NFHS-3, 2005-06 data by wealth index quartiles (Wall chart). New Delhi, India: Urban Health Resource Centre; 2008. Available from: http://www.uhrc.in/ downloads/wall-chart.pdf. accessed February 2014.

12. Shekhar C, Ram F. National Report on Evaluation of Functioning of Urban Health Posts/UrbanFamily Centres in India. Mumbai: International Institute for Population Sciences. 2013;3(2):103-6.

13. Sood A, Pahwa P. Existing practices and barriers to access of $\mathrm{MCH}$ services - a case study of residential urban slums of district Mohali, Punjab, India. Global J Med Public Health. 2013;2(4):1-8.

14. Sharma A, Pati S, Chakravarty N, Chauhan AS. Physicians' nutritional counselling practices: a study in district hospitals of Chhattisgarh. Int J Med Public Health. 2013:3:103-6.

15. Umesh K, Pathak P, Tandon M, Singh C, Pradhan R, Dwivedi SN. Micronutrient deficiency disorders amongst pregnant women in three urban slum communities of Delhi. Indian Pediatr. 1999;36:991-8.

16. Kumar R, Aslesh OP, Kumar A, Kapoor A, Sanan D, Wadhwa E, et al. Urban poor women do not increase their diet during pregnancy: a study from an urban resettlement colony in Delhi. India Int J Med Public Health. 2013:3:134-9.
17. Devasenapathy N, George MS, Ghosh Jerath S, Singh A, Negandhi H, Alagh $\mathrm{G}$, et al. Why women choose to give birth at home: a situational analysis from urban slums of Delhi. BMJ Open. 2014;4(5):e004401. doi: 10.1136/ bmjopen-2013-004401.

18. National Family Health Survey (NFHS-3), India, 2005-06: Delhi. Mumbai: IIPS Available at http://hetv.org/india/nfhs/nfhs3/NFHS-3-Delhi-state-report.pdf. (accessed on 9th June, 2014).

19. Nutritive Value of Indian Foods (NVIF) By C. Gopalan, B.V. Rama Sastri \& S.C. Balasubramanian, Revised \& Updated (1989) by B.S. Narasinga Rao, Y.G. Deosthala \& K.C. Pant (Reprinted 2007, 2011). National Institute of Nutrition, Indian Council of Medical Research, Hyderabad, India.

20. Nutrient Requirement and Recommended Dietary Allowances for Indians. A Report of the Expert Group of the ICMR 2010. India. National Institute of Nutrition: Hyderabad. http://icmr.nic.in/final/RDA-2010.pdf (accessed 15/3/2014).

21. Dietary Guidelines for Indians-A manual. Indian Council of Medical Research (ICMR). 2011. http://ninindia.org/Dietaryguidelinesforlndians-Finaldraft.pdf. (accessed 15/3/2014).

22. Preventing and Controlling Iron Deficiency Anaemia through Primary Health Care. A guide for Health Administrators and Program Managers. World Health Organisation. 1989. http://www.who.int/nutrition/publications/micronutrients/ anaemia_iron_deficiency/9241542497.pdf (accessed 24/3/2015).

23. Consultation WHOE. Appropriate body-mass index for Asian populations and its implications for policy and intervention strategies. Lancet. 2004;363 (9403):157-63. doi: 10.1016/S0140-6736(03)15268-3.

24. StataCorp. Stata Statistical Software: Release 13. College Station, TX: StataCorp LP; 2013.

25. Reshma MV, Ravi Kiran C, Nisha P, SobanKumar DR, Sundaresan A, Jayamurthy $P$. Trans fat content in labeled and unlabelled Indian bakery products including fried snacks. Int Food Res J. 2012;19(4):1609-14.

26. Agrawal A, Gupta R, Varma K, Mathur B. High trans fatty acid content in common Indian fast foods. Nutr Food Sci. 2008:38:564-9.

27. Das S, Bapat U, More NS, Chordhekar L, Joshi W, Osrin D. Prospective study of determinants and costs of home births in Mumbai slums. BMC Pregnancy Childbirth. 2010;10:38. doi: 10.1186/1471-2393-10-38.

28. Hazarika I. Women's reproductive health in slum populations in India: evidence from NFHS-3. J Urban Health. 2010;87(2):264-77. doi: 10.1007/ s11524-009-9421-0.

29. Jain A, Gupta SC, Misra SK. Quality of antenatal services in district Agra. Indian J Prev Soc Med. 2011:42(1):9-13.

30. Durga RP, Sudhakar BM, Narsimha Rao VL. Persistent traditional practices among tribes of North Coastal Andhra Pradesh. Stud Tribes Tribals. 2006:1:53-5.

31. Kinfu Y, Dal Poz MR, Mercer H, Evans DB. The health worker shortage in Africa: are enough physicians and nurses being trained? Bull World Health Organ. 2009;87(3):225-30.

32. Wakabi W. Extension workers drive Ethiopia's primary health care. Lancet. 2008;372(9642):880.

33. Afework MF, Admassu K, Mekonnen A, Hagos S, Asegid M, Ahmed S. Effect of an innovative community based health program on maternal health service utilization in north and south central Ethiopia: a community based cross sectional study. Reprod Health. 2014;11:28. doi: 10.1186/1742-4755-11-28.

34. El Arifeen S, Christou A, Reichenbach L, Osman FA, Azad K, Islam KS, et al. Community-based approaches and partnerships: innovations in health-service delivery in Bangladesh. Lancet. 2013;382(9909):2012-26. doi: 10.1016/S0140-6736(13)62149-2.

35. Temiss W. Health extension program in Ethiopia: towards better access to health services for the rural poor. Federal democratic republic of Ethiopia, Ministry of health quarterly. Health Bull. 2008;1(1):3-9.

36. Sunguya BF, Poudel KC, Mlunde LB, Shakya P, Urassa DP, Jimba M, et al. Effectiveness of nutrition training of health workers toward improving caregivers' feeding practices for children aged six months to two years: a systematic review. Nutr J. 2013;12:66. doi: 10.1186/1475-2891-12-66. 